\title{
Simulation of Hydrate Plug Prevention in Natural Gas Pipeline from Bohai Bay to Onshore Facilities in China
}

\author{
Solomon Aforkoghene Aromada ${ }^{1 *}$, Bjørn Kvamme ${ }^{1}$ \\ ${ }^{1}$ Department of Physics and Technology, University of Bergen, Allegaten 55, 5007 Bergen, Norway; \\ *Solomon.Aromada@student.uib.no, saromada@gmail.com \\ 2Strategic Carbon LLC, Vestre Holbergsallmenningen 17, 5011 Bergen, Norway; kvamme@strategic-carbonllc.com
}

SNE 31(3), 2021, 151-157, DOI: 10.11128/sne.31.tn.10576 Received: March 10, 2021 (Selected EUROSIM 2019 Postconf. Publ.); Revised: Sept. 1, 2021; Accepted: September 3, 2021 SNE - Simulation Notes Europe, ARGESIM Publisher Vienna ISSN Print 2305-9974, Online 2306-0271, www.sne-journal.org

Abstract. Natural gas hydrates occasionally plug the 58 $\mathrm{km}$ subsea pipeline that transports natural gas from Platform QK18-1 in southwest of Bohai Bay to the processing facility onshore in Northeast China. This is because it is a wet gas subsea pipeline that operates at high pressures and low temperatures, which are the conditions that are appropriate for hydrate formation to occur. In this study, we proposed that the best way to prevent the occasional plugging of the pipeline is to rightly evaluate the upper limit of water that can be permitted in the bulk gas and dehydrate the gas accordingly before transport. Current industrial techniques are mainly based on water dewpoint evaluations. In our recent work we have proposed another approach that considers the impact of the rust (Hematite) on the internal walls of pipelines. These two methods have been used for this study. The results of the method of adsorption of water onto rusty (Hematite) surfaces suggest that the current approach (dewpoint method) overestimates the safe-limit of water about 18 to 19 times higher. Thus, the risk of hydrate formation may still exist if the dewpoint method is used as basis for drying the gas. Sensitivity analysis shows the influence of pressure on the upper limit of water- the higher the pressure the lower the maximum concentration of water that is safe to accompany the gas. Our calculations were done using a FORTRAN code that utilize thermodynamic data from molecular dynamics simulation.

\section{Introduction}

Hydrate discovery is dated back to 1810 and credited to Sir Humphrey Davy [1-3]. But natural gas hydrate (NGH) formation in pipeline transporting natural gas became a major research focus in the 1930's through the work of Hammerschmidt [4]. NGH are non-stoichiometric crystalline inclusion compounds formed when hydrogen-bonded water molecules form three-dimensional solid cage-like structures with cavities which entrap suitably small sized molecules of certain gases and volatile liquids known as guest molecules. Methane, ethane, propane, isobutane, carbon dioxide $\left(\mathrm{CO}_{2}\right)$ and hydrogen sulphide $\left(\mathrm{H}_{2} \mathrm{~S}\right)[5,6]$ are guest molecules that can form hydrate in their pure form. Hydrates are ice-like solid substances that form at high pressures and low temperatures conditions when free water (liquid) is available in a gas containing guest molecules. Hydrate formation is a crucial flow assurance challenge to the oil and gas industry since water is always produced together with hydrocarbons. This water can drop out of the bulk gas. With the appropriate thermodynamic conditions of high pressure and low temperature [6-8], and favourable mass and heat transport, this could lead to hydrate formation. Subsequently, accumulation and agglomeration of the formed hydrate can occur and eventually lead to plugging [4] of pipelines. This results in stopping of operations which means economic losses [9]. Sometimes there could be destruction $[9,10]$ of pipelines and equipment, and even loss of live [5].

There are many pipeline networks all over the world transporting hydrocarbons [11]. In this work we have focused on the $58 \mathrm{~km}$ subsea pipeline [12] from Platform QK18-1 in southwest of Bohai Bay (part of the Bohai Gulf), transporting natural gas to the processing facility 
onshore in Northeast China. It is a wet gas subsea pipeline and it is exposed to elevated pressure and low temperature [12]. Plugging of the pipeline by hydrate occurs once in a while [12]. Li et al. [12] performed an experimental study on the pipeline and suggested the following solutions: pressure reduction or raising the temperature (heating the pipeline), dehydration of gas before subsea pipeline transport, and thirdly, addition of chemical additives such as kinetic hydrate inhibitors (KHI), to ensure safe operations.

In this work, our focus is on the second recommendation. This is also in accordance with what $\mathrm{Li}$ et al. [12] proposed as the best choice out of their three recommendations. However, their work did not go into details of how to estimate the upper limit of water content in the gas for prevention of hydrate formation in the subsea pipeline. In a recent work [13], we hproposed an alternative approach for evaluating the upper limit of water in natural gas during pipeline transport to avoid the risk of hydrate formation. The study focused on hydrocarbon components of methane, ethane, propane and isobutane which are the primary hydrocarbon hydrate guest molecules. Therefore, there is a need to carry out this study with a real and specific gas field data. This also involves some content of inorganic gases like $\mathrm{CO}_{2}$ which is a very strong hydrate former. Nitrogen cannot form hydrate in its pure form [14] but can still enter hydrate which is mainly stabilized by other components. In the other end of the guest molecule size scale is normal butane [15-17], which does not make hydrate as pure component, but gauche conformation can fit into large cavity of structure I when methane fills small cavities. Both trans and gauche conformations fit large cavities of structure II although the trans configuration gives low stabilization and will only form hydrate with methane or other good hydrate former in small cavities.

\section{Thermodynamics of Hydrate: Description and Validation of Model}

We used residual thermodynamics with Soave-RedlichKwong (SRK) equation of state [18] for all components in each phase (hydrate, ice and liquid water). We did that by making use of molecular dynamics (MD) simulations results for water in empty hydrates, liquid water, and ice phases [19]. We used equation (1) to estimate the chemical potential of component $j$ in the gas phase.
To ensure the same reference value for free energy of all the estimates of chemical potentials, regardless of the phase, ideal gas is used as the reference state:

$$
\begin{gathered}
\mu_{j}(T, P, \vec{y})=\mu_{j}^{\text {ideal gas }}(T, P, \vec{y})+R T \ln \emptyset_{j}(T, P, \vec{y}) \\
\lim \left(\emptyset_{i}\right) \rightarrow 1.0 \text {...for ideal gas }
\end{gathered}
$$

Where $\emptyset_{i}$ is the fugacity coefficient for component $j$ in the given phase, $R$ is universal gas constant, $\vec{y}$ is the mole fraction vector of the gas, $P$ and $T$ are pressure and temperature respectively. The chemical potential of component $j$ in water is estimated as:

$$
\begin{gathered}
\mu_{j}(T, P, \vec{x})=\mu_{j}^{\text {ideal liquid }}(T, P, \vec{x})+R T \ln \gamma_{j}(T, P, \vec{x}) \\
\lim \left(\gamma_{j}\right) \rightarrow 1.0 \text { when } x_{j} \rightarrow 1.0
\end{gathered}
$$

Where $\gamma_{j}$ stands for the activity coefficient of component $j$ in the liquid phase and $\vec{x}$ is the mole fraction vector of the liquid. It is also proper to use a reference state of infinite dilution since the solubility of methane and higher hydrocarbons in water is low:

$$
\begin{aligned}
& \mu_{j}^{\mathrm{H}_{2} \mathrm{O}}(T, P, \vec{x})=\mu_{j}^{\mathrm{H}_{2} \mathrm{O}, \infty}(T, P, \vec{x})+ \\
& R T \ln \left[x_{j}^{\mathrm{H}_{2} \mathrm{O}} \cdot \gamma_{j}^{\mathrm{H}_{2} \mathrm{O}, \infty}(T, P, \vec{x})\right] \\
& \lim \left(\gamma_{j}^{\mathrm{H}_{2} \mathrm{O}, \infty}\right) \quad \text { when } x_{j} \rightarrow 0
\end{aligned}
$$

Where $\mu_{j}^{\mathrm{H}_{2} \mathrm{O}, \infty}$ represents the chemical potential of component $j$ in water, $\infty$ denotes infinite dilution, $\gamma_{j}^{\mathrm{H}_{2} \mathrm{O}, \infty}$ stands for activity coefficient of component $j$ in aqueous phase based on the same reference state. The solubility of methane and higher hydrocarbons are each very low. Thus, equation (4) could be applied together with equation $(3)$ :

$\mu_{j}^{i}(T, P, \vec{x}) \approx \mu_{j}^{i, \infty}(T, P, \vec{x})+R T \ln \left[x_{j}^{i} \cdot \gamma_{j}^{i, \infty}(T, P, \vec{x})\right]$

Superscript $i$ stands for different phases with low solubility, while subscript $j$ represents different components. We evaluated the chemical potential of water in hydrate using the statistical mechanical model for water in hydrate (equation 5). This is a typical Langmuir type of adsorption model. The version we used is different from that of van der Waal and Platteuw [20] which assumes rigid lattice. 
It is the one proposed by Kvamme and Tanaka [19]. This one takes into account the movements of the lattice and the corresponding impacts of different guest molecules. That is, the collisions between guest molecules and water which are adequately strong enough to affect the water motion.

$\mu_{H_{2} \mathrm{O}}^{(\mathrm{H})}=\mu_{\mathrm{H}_{2} \mathrm{O}}^{(0, H)}-\sum_{i=1}^{2} R \cdot T \cdot v_{i} \cdot \ln \left(1+\sum_{j=1}^{n_{\text {guest }}} h_{i j}\right)$

Where $H$ stands for hydrate phase, $\mu_{\mathrm{H}_{2} \mathrm{O}}^{(\mathrm{O})}$ refers to the chemical potential of water in hydrate, $\mu_{\mathrm{H}_{2} \mathrm{O}}^{(0, \mathrm{O})}$ signifies the chemical potential of water in empty hydrate structure, and $v_{i}$ is the fraction of cavity type $i$ per water molecule. The $h_{i j}$ in equation (11) is the canonical cavity partition function of component $j$ in cavity type $i$, and $n_{\text {guest }}$ is the number of guest molecules in the system. We evaluated the canonical partition function using the relation:

$$
h_{i j}=e^{-\beta\left(\mu_{i}^{H}-\Delta g_{i j}^{i n c}\right)}
$$

Where $\beta$ is inverse of gas constant times temperature $\left(\frac{1}{R . T}\right)$, and $\Delta g_{i j}^{i n c}$ is the effects of inclusion of the guest molecules $j$ in the cavity $i$ on hydrate water. The free energy change related to hydrate phase transition $\left(\Delta \mathrm{g}^{H}\right)$ is evaluated using equation (14):

$$
\Delta g^{H}=\delta \sum_{j=1}^{n^{H}} x_{j}^{H}\left(\mu_{j}^{H}-\mu_{j}^{P}\right)
$$

Where $H$ refers to hydrate phase of molecule $j, P$ here is parent phase of molecule $j$. And equation (15) gives the relation between the filling fraction, the mole fractions and cavity partition function as shown below:

$$
\theta_{i j}=\frac{x_{i j}^{H}}{v_{j}\left(1-x_{T}\right)}=\frac{h_{i j}}{1+\sum_{j} h_{i j}}
$$

Where $x_{T}$ signifies total mole fractions of all hydrate formers in the hydrate, $\theta_{i j}$ refers to the filling fraction of component $j$ in cavity type $i$, and $x_{i j}^{H}$ stands for mole fraction of component $j$ in cavity type $i$.

\section{Composition of the Natural Gas from Bohai Bay}

The composition of the wet natural gas from the southwestern Bohai Bay and the dry gas (City gas) used by Reference [12] are given in the Table 1. All other hydrocarbon components after $\mathrm{iC}_{4}$, that is $\mathrm{nC}_{4}$ and $\mathrm{C}_{5+}$ and $\mathrm{CO}$ are not considered in this study as they are not relevant. Therefore, the molar compositions are normalised.

\begin{tabular}{ccc}
\hline \multirow{2}{*}{ Components } & \multicolumn{2}{c}{ Composition [Mole fractions] } \\
& Wet gas from subsea pipeline & Dry gas \\
\hline $\mathrm{C}_{1}$ & 0.8868 & 0.9259 \\
$\mathrm{C}_{2}$ & 0.0612 & 0.0319 \\
$\mathrm{C}_{3}$ & 0.0332 & 0.0136 \\
$i \mathrm{C}_{4}$ & 0.0066 & 0.0034 \\
$\mathrm{CO}_{2}$ & 0.0072 & 0.0093 \\
$\mathrm{~N}_{2}$ & 0.0050 & 0.0159 \\
\hline
\end{tabular}

Table 1. Composition of the Natural gas from Bohai Bay [12]

\section{Model Validation}

The estimates of hydrate equilibrium pressures from our theoretical model used for the simulations in FORTRAN are compared with experimental data relevant for the compositions of the gas in this study. Experimental data of Reference [21] (Figure 1) and Reference [22] (Figure 2) are the best we could find for this comparison based on closeness to the composition of the gas.

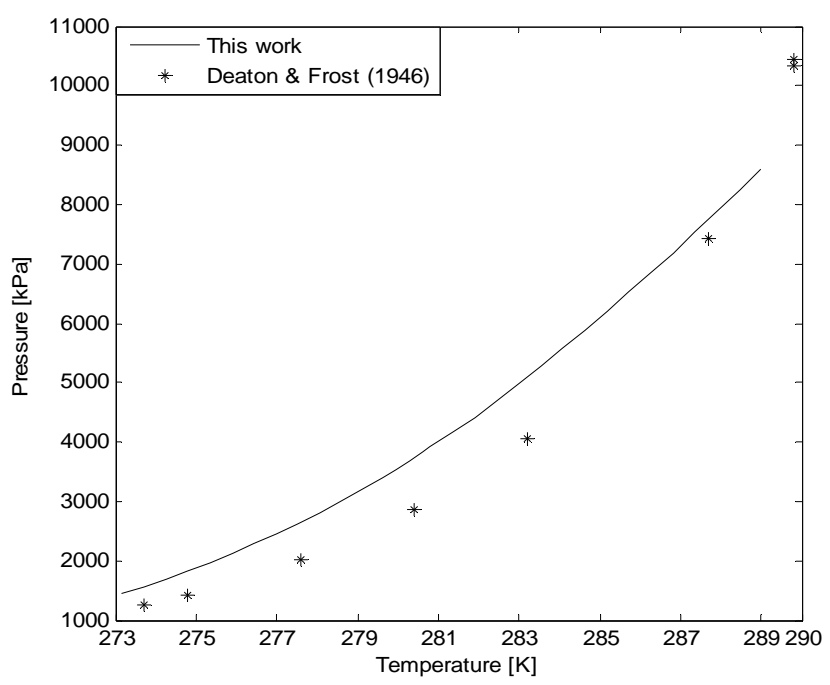

Figure 1. Estimated equilibrium pressures for hydrate formed from a gas mixture containing 96.50 mole $\% \mathrm{CH}_{4}, 0.90$ mole $\% \mathrm{C}_{2} \mathrm{H}_{6}$, 1.80 mole $\% \mathrm{C}_{3} \mathrm{H}_{8}, 0.20$ mole $\% \mathrm{CO}_{2}$, and 0.60 mole $\% \mathrm{~N}_{2}$ [21].

It is important to state that the free energy of inclusions has been evaluated by MD simulations. And that we did not tune the model (no empirical data fitting was done) because our priority is to keep the statistical mechanical model [19] free of adjustable parameters in all terms.

These comprises the chemical potentials of empty hydrate, ice, and liquid water. Therefore, a fair qualitative 
agreement is adequately acceptable for this study. So, the expectation is not perfect match with experimental data. The deviations are satisfactorily acceptable for further illustration of the maximum concentration of water content that should be allowed without the risk of hydrate formation.

It is also imperative to point out that more than one hydrate, that is having different densities, composition, and free energies do result from multicomponent gas mixtures $[8,13]$. We know that the most stable hydrate will first form [13] based on the combined first and second laws of thermodynamics, then formation of a variety of hydrate compositions will occur. Therefore, the hydrate that would probably form in case of Figure 1 ought to be a mixture both structure I and II. But based on the very low concentration of propane, Reference [21] assumed only structure I hydrate is formed. In Figure 2, we took the presence of propane into consideration (the solid line) and disregarded it (dash-dot line) in a second run. That revealed that Wilcox et al. [22] also assumed only structure I hydrate is formed. The solid line in Figure 2 shows that there is a phase split by the propane (liquid and gas) at $278.5 \mathrm{~K}$ [7]. Most literature are wrong for straightening the curve as it is not the real situation. $\mathrm{CO}_{2}$ also undergo a phase split [24] as pressure increases. Therefore, the final hydrate that would form as in these figures could likely be a mixture of several hydrates (sI and sII) with varying compositions of the initial hydrate formers from gas or liquid will result [13].

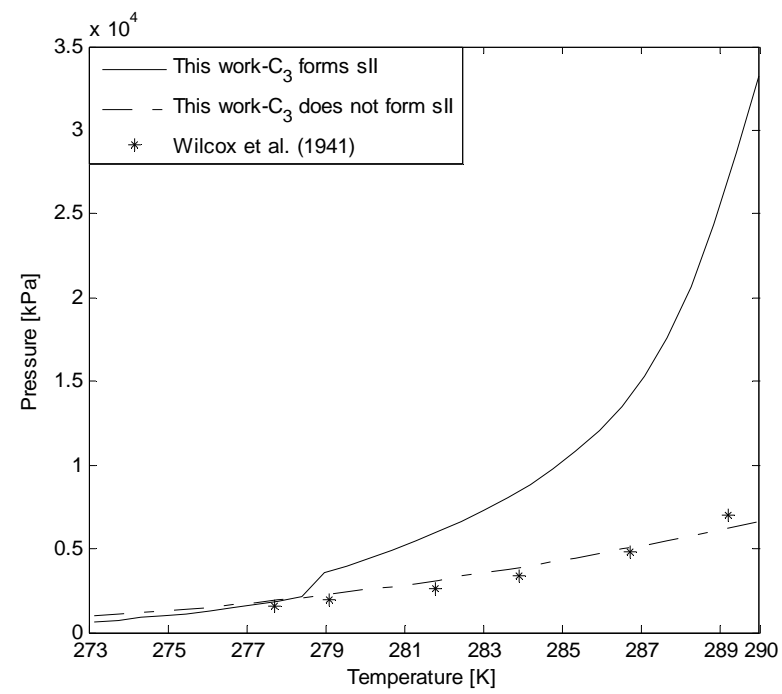

Fig.2. Estimated equilibrium pressures for hydrate formed from a gas mixture containing 93.20 mole \% $\mathrm{CH}_{4}, 4.25$ mole $\% \mathrm{C}_{2} \mathrm{H}_{6}, 1.61$ mole $\% \mathrm{C}_{3} \mathrm{H}_{8}, 0.51$ mole $\% \mathrm{CO}_{2}$, and 0.43 mole $\% \mathrm{~N}_{2}[22]$.

\section{Safe-limits of Water in Natural Gas from Bohai Bay through Subsea Pipeline to Onshore Facilities in China and the City Gas}

\subsection{Alternative evaluation approaches: Impact of rust}

The typical industrial practice for evaluating the risk of hydrate formation during pipeline transport of natural gas assumes that liquid water will condense out from the bulk gas stream to form a separate liquid water phase that can subsequently cause hydrate nucleation. This is done by estimating the dew-point pressure of water in the gas stream, then, check whether the computed dew-point pressure at the local temperature is within the temperature and pressure projection of the hydrate stability zone. If it is, it means water will drop out as liquid droplets. Afterwards, the theoretical amount of water that would condense out can be estimated and steps are taken to dry the gas. Or else, the necessary amount of a hydrate inhibitor that can adequately shift the hydrate stability curve's pressure and temperature projections beyond the risk zone is calculated and applied in the system to avoid hydrate formation. This we refer to as the dew point method.

In our recent work [13], we proposed an alternative approach for evaluation of the risk of hydrate formation in pipelines for gas mixtures containing methane, ethane, propane, and iso-butane which we call the Hematite approach. By Hematite we mean the most dominant and most thermodynamically stable form of rust. In this study, we have applied both methods (dew point method and hematite approach) to study a real gas mixture [12], a wet gas transported from offshore China to onshore processing facility using a $58 \mathrm{~km}$ subsea pipeline that is exposed to high pressures and low temperatures. However, in this situation, the gas mixture contains some inorganic gases, $\mathrm{CO}_{2}$ that is a strong hydrate former compared to the hydrocarbons, and nitrogen that can also fill the small cages of sI hydrate in the presence of a helping molecule (methane). Nitrogen in its pure form cannot form hydrate [6], rather it has a dilution effect, that is why it has been proposed for use to reduce the reactivity of $\mathrm{CO}_{2}$ during a simultaneous $\mathrm{CO}_{2}$ storage in form of $\mathrm{CO}_{2}$ hydrate and production of $\mathrm{CH}_{4}$ [23]. 
The results of our investigation using the two approaches are presented in Figure 3 for the wet gas and Figure 4 in the case of the dry gas. Pressure range of $5000-25000 \mathrm{kPa}$ and temperature range of $273-280 \mathrm{~K}$ are used because these are the relevant ranges in such operations, for instance in the North Sea of Norway [6]. The maximum concentration of water that can be permitted in both the wet gas and dry gas are plotted in logarithm to base $10(\log 10)$ to enable us plot results with both methods on the same figure. The only essence of including the dry gas in this analysis is merely for sensitivity analysis: to show how a slight change in composition of the same components in the gas mixture can cause slight change in water tolerance as can be observed in Figure 5 and Figure 6.

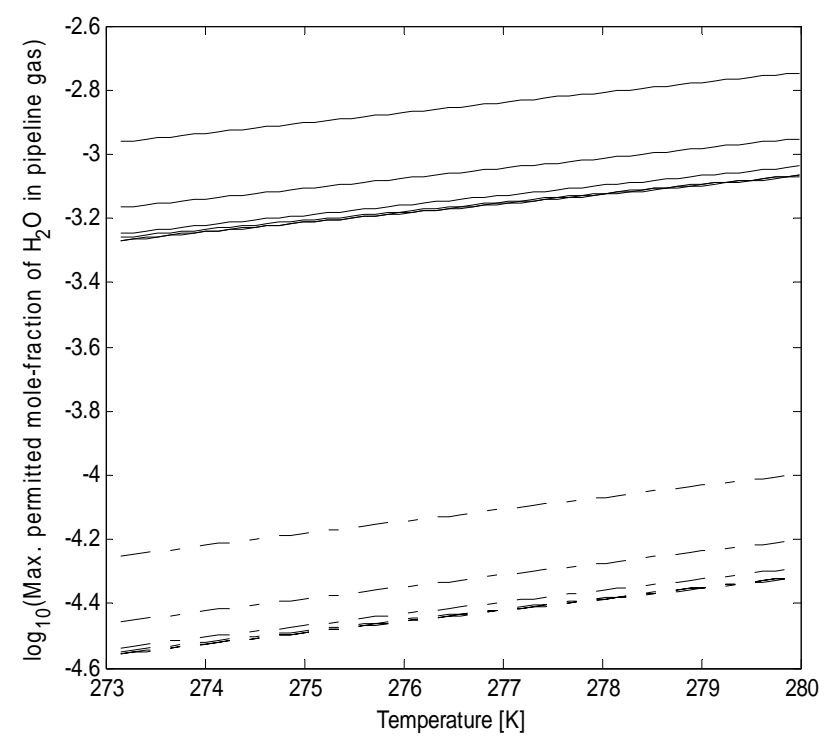

Figure 3. Estimated maximum concentration of water that should be permitted in the pipeline gas (wet gas) in logarithm to the base $10\left(\log _{10}\right)$ vs temperature. Upper solid lines (-) represent estimates with the conventional dew point calculation, lines from top to bottom are for $5000 \mathrm{kPa}, 9000 \mathrm{kPa}, 13000 \mathrm{kPa}, 17000 \mathrm{kPa}, 21000 \mathrm{kPa}$, and $25000 \mathrm{kPa}$ respectively. Lower dash-dot lines (-.) represent estimates with the approach of adsorption of water onto hematite, lines from top to bottom are also for $5000 \mathrm{kPa}, 9000 \mathrm{kPa}, 13000 \mathrm{kPa}, 17000 \mathrm{kPa}, 21000$ $\mathrm{kPa}$, and $25000 \mathrm{kPa}$ respectively.

After processing the gas, the dry gas (city gas) is slightly richer in the lightest hydrocarbon component (methane) and that also caused the permitted water concentration to also move up slightly, which indicate that presence of the heavier hydrocarbon components like ethane, propane, and isobutane means a lower allowable water content $[6,7,13]$ to avoid the risk of hydrate formation in a subsea pipeline operating at a high pressure and low temperature.

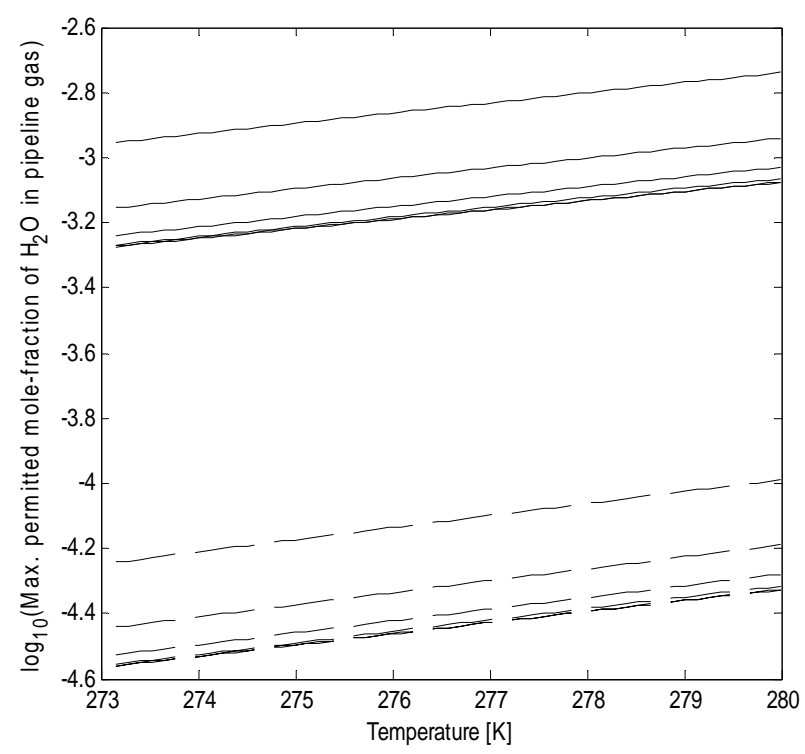

Figure 4. Estimated maximum concentration of water that should be permitted in the pipeline gas (dry gas) in logarithm to the base $10\left(\log _{10}\right)$ vs temperature. Upper solid lines (-) represent estimates with the conventional dew point calculation, lines from top to bottom are for $5000 \mathrm{kPa}, 9000 \mathrm{kPa}, 13000 \mathrm{kPa}, 17000$ $\mathrm{kPa}, 21000 \mathrm{kPa}$, and $25000 \mathrm{kPa}$ respectively. Lower dash lines (--) represent estimates with the approach of adsorption of water onto hematite, lines from top to bottom are also for $5000 \mathrm{kPa}, 9000$ $\mathrm{kPa}, 13000 \mathrm{kPa}, 17000 \mathrm{kPa}, 21000 \mathrm{kPa}$, and $25000 \mathrm{kPa}$ respectively.

How much lower depends on the amount of the higher hydrocarbons present in mixture with methane.

In this analysis, estimation of maximum allowable water content using the dew point method instead of the new approach may not ensure safe operation in respect of hydrate formation, since rust (Hematite) which is usually present in surfaces of inner walls of pipelines would still make water available through the mechanism of adsorption even at much lower mole-fractions than what is estimated by the dew point method. Hematite acts as a catalyst that helps to pull out the water from the bulk gas stream through adsorption, then hydrate can subsequently form slightly outside of the first two or three water layers of about $1 \mathrm{~nm}$. Using the dew point approach overestimates the safe-limit of water about 18 to 19 times more than what is calculated by the method of water adsorption on Hematite. Additionally, the chemical potential of adsorbed water is about $-3.4 \mathrm{~kJ} / \mathrm{mol}$ lower $[6,7]$ than that of ordinary liquid water. 
This mean absorbed water on rusty surfaces will more readily lead to hydrate formation than ordinary liquid water based on the combined first and second laws of thermodynamics (thermodynamic systems strive towards the least free energy). Therefore, the approach of adsorption of water on rusty surfaces dominates, and possibly will have an impact on designing natural gas dehydration systems.

\subsection{Impacts of temperature and pressure}

The work of Reference [12] focused on the impacts of pressure on temperature, density, and flowrate. But in this work our focus is on the recommended best measure to prevent [12] hydrate formation, that is reducing the water concentration to allowable limits.

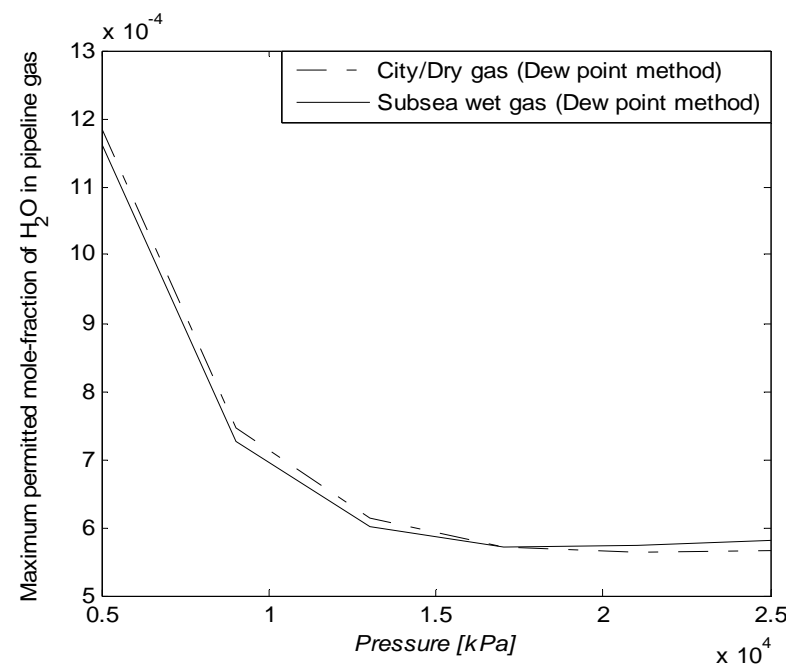

Figure 5. Impact of pressure on the maximum amount of water that should be permitted in the pipeline gases, conventional dew point estimates

The higher the temperature, the higher the upper limit of water in the gas stream to prevent hydrate formation during transport through the subsea pipeline as can be seen in Figure 3 and Figure 4. While Figure 5 and Figure 6 show that the higher the pressure, the lower the safe-limit of water in the gas. The results are the same with evaluations by both approaches. The only difference is the absolute values of mole-fractions of water. The last three lines for pressures of $17000 \mathrm{kPa}, 21000 \mathrm{kPa}$ and 25000 $\mathrm{kPa}$ as can be observed in Figure 3 and Figure 4., almost overlap. Figure 5 and Figure 6 make that clearer. This is a result of the high density of the non-polar hydrocarbons at these very high pressures.
The maximum water content becomes almost insensitive to increase in pressure due to the resistance of the tightly packed molecules of the non-polar hydrocarbon gases present in the system. It can also be seen on Figure 5 and Figure 6 that the slightly heavier wet gas curve crosses that of the slightly lighter city (dry) gas. This only shows that the heavier wet gas responds slightly faster in resistance to pressure than the slightly lighter city gas.

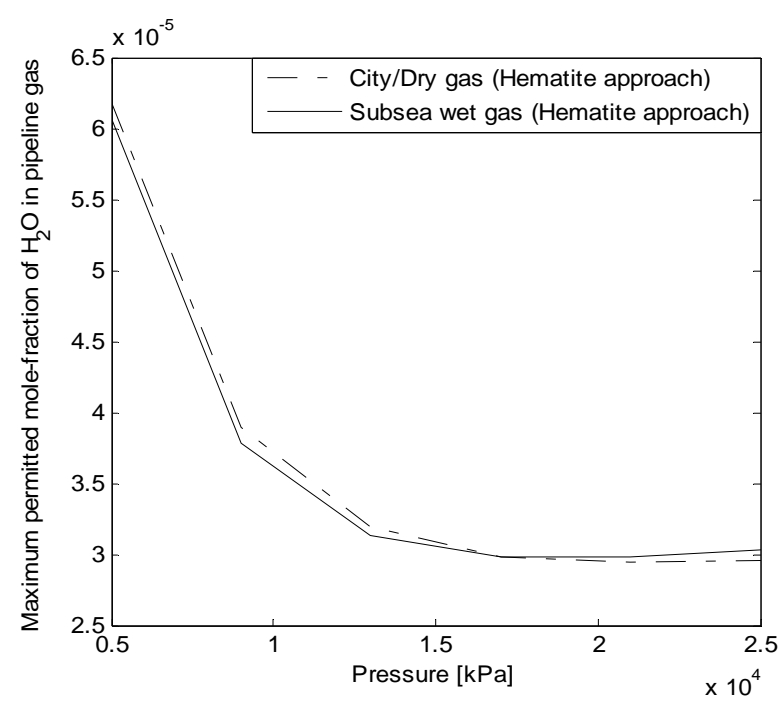

Figure 6. Impact of pressure on the maximum amount of water that should be permitted in the pipeline gases, hematite approach.

\section{Conclusion}

We conducted a study on how to prevent the occasional plugging of the wet gas subsea pipeline that transports natural gas from Platform QK18-1 in southwest of Bohai Bay to the processing facility onshore in Northeast China. This pipeline is operated at temperature and pressure conditions that are suitable for hydrate to form: high pressures and low temperatures. The thermodynamic scheme we used was simulated using a FORTRAN code based on the results of Kvamme and Tanaka molecular dynamics simulations. We used residual thermodynamics by means of Soave-Redlich-Kwong (SRK) equation of state for each component in every phase: hydrate, ice, and liquid water phases. The typical schemes currently employed by the petroleum industry for hydrate risk analysis are normally based on evaluation of water dewpoint, with the assumption that water will drop out of the bulk gas at the temperature and pressure conditions of dewpoint if the amount of water is up to or above the dewpoint concentration. 
This water can subsequently lead to hydrate formation and eventually to plugging of the pipeline. In our recent work, we have proposed an alternative route for water to drop out of the bulk gas, that is through the process of adsorption of water onto rusty (Hematite) surfaces of the internal walls of pipelines. Pipelines are usually rusty before they are mounted in place for natural gas transport. The results of the method of adsorption of water onto rusty (Hematite) surfaces suggest that the current method based on water dewpoint calculation overestimates the allowable upper limit of water about 18 to 19 times higher. This means the risk of hydrate forming in the subsea pipeline may still exist if the dewpoint method is used. A pressure sensitivity analysis was also performed, and it shows that the higher the pressure the lower the maximum content of water that is safe to follow the gas.

\section{References}

[1] Campbel J M. Gas Conditioning and Processing. Vol. 1. Basic Principles. 157-200, (2003).

[2] Schroeder W: In Ahren's Sammlung Chemischer und Chemisch-Technik Vortrage, 21- 71, (1926-28). Cross referenced from [4].

[3] Vafaei M T. Reactive transport modelling of hydrate phase transition dynamics in porous media. PhD Dissertation, University of Bergen, Norway, 2015.

[4] Hammerschmidt E G. Formation of gas hydrates in natural gas transmission lines. Industrial \& Engineering Chemistry 26(8), 851-855 (1934).

[5] Sloan Jr E D, Koh C. Clathrate hydrates of natural gases. $3^{\text {rd }}$ edn. Boca Raton, Florida CRC press, (2007).

[6] Kvamme B, Aromada S A. Risk of hydrate formation during the processing and transport of Troll gas from the North Sea. Journal of Chemical \& Engineering Data 62(7), 2163-2177 (2017). DOI: $10.1021 /$ acs.jced.7b00256

[7] Kvamme B, Aromada S A. Alternative routes to hydrate formation during processing and transport of natural gas with a significant amount of $\mathrm{CO}_{2}$ : Sleipner Gas as a Case Study. Journal of Chemical \& Engineering Data 63(3), 832-844 (2018). DOI: 10.1021/acs.jced.7b00983

[8] Aromada, S A, Kvamme B. Impacts of $\mathrm{CO}_{2}$ and $\mathrm{H}_{2} \mathrm{~S}$ on the risk of hydrate formation during pipeline transport of natural gas. Frontiers of Chemical Science and Engineering, 1-12 (2019). DOI: $10.1007 / \mathrm{s} 11705-019-1795-2$

[9] Makogon, Y. F.: Natural gas hydrates-A promising source of energy. Journal of Natural Gas Science \& Engineering 2, 49-59 (2010). DOI: $10.1016 /$ j.jngse.2009.12.004
[10] Woehler F. Krystallisirtes Schwefelwasserstoff-Hydrat. Justus Liebigs Annalen der Chemie 33, 125-126 (1840) Cross referenced from Hammerschmidt (1934)

[11] Chartsbin Website, Total Length of Pipelines for Transportation by Country, http://chartsbin.com/view/1322, last accessed 2017/01/16.

[12] ] Li W, Gong J, Lü X, Zhao J, Feng Y, Yu D. A study of hydrate plug formation in a subsea natural gas pipeline using a novel high-pressure flow loop. Petroleum Science 10(1), 97-105 (2013). DOI: $10.1007 / \mathrm{s} 12182-013-0255-8$

[13] Aromada S A, Kvamme B. New approach for evaluating the risk of hydrate formation during transport of hydrocarbon hydrate formers of sI and sII. AIChE Journal 65(3), 1097-1110, (2019). DOI:_ 10.1002/aic.16493

[14] Kvamme B. Fundamentals of Natural Gas Hydrates and Practical Implications. Unpublished Work: PTEK 232, Course Material, Spring Semester 2017, Dept of Physics and Technology, University of Bergen, Norway, 2017.

[15] Kumar S. Gas Production Engineering. Gulf Publishing Company, Book Division, (1987).

[16] John V, Holder G. Hydrates of methane+ butane below the ice point. Journal of Chemical and Engineering Data 27, 18-21 (1982).

[17] Ng H-J, Robinson D B. Equilibrium-phase properties of the toluene-carbon dioxide system, Journal of Chemical and Engineering data 23, 325-327 (1978).

[18] Soave G. Equilibrium constants from a modified RedlichKwong equation of state. Chemical Engineering Science 27, 1197-1203, (1972).

[19] Kvamme B, Tanaka H: Thermodynamic stability of hydrates for ethane, ethylene, and carbon dioxide. The Journal of Physical Chemistry 99(18), 7114-7119 (1995).

[20] van der Waals J H, Platteeuw J C. Clathrate solutions. Advance Chemical Physics 2,1-57 (1959).

[21] Deaton W M, Frost Jr E M. Gas hydrate composition and equilibrium data. Oil \& Gas Journal 45, 170-178(1946).

[22] Wilcox W I, Carson D B, Katz D L. Natural gas hydrates. Industrial \& Engineering Chemistry 33(5), 662-665 (1941).

[23] Kvamme B, Aromada S A, Kuznetsova T, Gjerstad P B, Canonge P C, Zarifi M. Maximum tolerance for water content at various stages of a natuna production. Heat and Mass Transfer 1-21 (2018). DOI: $10.1007 / \mathrm{s} 00231-018-2490-4$

[24] Aromada S A, Kvamme B, Wei N, Saeidi N. Enthalpies of hydrate formation and dissociation from residual thermodynamics. Energies, 12(24), 4726 (2019). 